\title{
Effects of n-3 fatty acids on growth, antioxidant status, and immunity of preweaned dairy calves
}

\author{
K. Śpitalniak-Bajerska, ${ }^{1}$ A. Szumny, ${ }^{2}$ K. Pogoda-Sewerniak, ${ }^{1}$ and R. Kupczyński ${ }^{1 *}$ (]) \\ ${ }^{1}$ Department of Environment Hygiene and Animal Welfare, Faculty of Biology and Animal Science, \\ Wroclaw University of Environmental and Life Sciences, 51-630 Poland \\ ${ }^{2}$ Department of Chemistry, Wroclaw University of Environmental and Life Sciences, 51-630 Poland
}

\section{ABSTRACT}

This study aimed to estimate the influences of flax oil and a mixture of ethyl esters of fatty acids from flax oil added to a milk replacer (MR) formulation on the biochemical, immunological, and antioxidant status of blood, production parameters, and health of calves. Twenty-seven Holstein-Frisian calves were assigned to 3 groups: the control group without fat added to the diet $(\mathrm{CON}, \mathrm{n}=9)$, a group receiving ethyl esters of flax oil $(10 \mathrm{~g} / \mathrm{d})$ with lyophilized apples (25 g; MRE), or a group receiving flax oil $(10 \mathrm{~g} / \mathrm{d})$ with lyophilized apples (25 g; MRL). The study was conducted from d 14 to d 42 of life. Intake of MR and feed were recorded daily, and fecal scores, rectal temperature, and body weight were recorded weekly. Laboratory blood tests were conducted every $7 \mathrm{~d}$ from d 14 to 42 . Supplementation with the formulation containing ethyl esters of flax oil (MRE) positively affected health, average daily weight gain, growth rate, and feed efficiency. Intake of the starter feed was lower in the calves receiving the formulation with flax oil (MRL). The MRE formulations lowered the concentrations of triglycerides, total cholesterol, and LDL fraction in blood serum and decreased the total antioxidant capacity (TAS) and levels of glutathione peroxidase (GPx). The MRL formulation increased TAS and GPx levels in blood serum. The MRE treatment limited the circulating levels of tumor necrosis factor. The MRE and MRL preparations lowered the concentration of SFA (C16:0, C18:0, C18:1) in blood serum, and MRE significantly increased levels of $\alpha$-linolenic acid. The MRE and MRL preparations beneficially affected production and physiological parameters. Our data support the idea that supplementation with n-3 fatty acids improves calf growth and metabolic and oxidative functions in young calves.

Received May 21, 2019.

Accepted November 14, 2019.

*Corresponding author: robert.kupczynski@upwr.edu.pl
Key words: calf, fatty acid, flax oil, growth, immunity

\section{INTRODUCTION}

Calf health and growth are significant factors in cattle production all over the world. The first weeks of a calf's life particularly have a key effect on its future performance and on production cost-effectiveness (Bateman et al., 2012; Garcia et al., 2016). Calf milk replacers (MR) tend to include various additives, such as protein-iron complex, butyrates, canola, linseed, and fish oil (Fokkink et al., 2009; Górka et al. 2011a; Hill et al., 2011; Kupczyński et al., 2017). The use of additives, especially those rich in PUFA, affects not only BW gain but also immune responses, antioxidant status, and overall metabolism (Calder et al., 2002; Hill et al., 2011; Karcher et al., 2014; Garcia et al., 2015).

Based on previous studies, adding PUFA to MR improves ADG and reduces the symptoms of diarrhea and inflammatory conditions caused by viral or bacterial infections (Hill et al., 2011). Fatty acids (FA) are interrelated in their functions. Supplementation with PUFA increases the percentage of PUFA in the phospholipid fraction of immune cells (Calder, 2008), which might modulate the functioning of the immune system. Suitable levels of linoleic acid (LA) and $\alpha$-linolenic acid (ALA) in diets might affect the immune response in the case of high exposure of the body to antigens. A suitable level of LA, which is a precursor of cytokinins and eicosanoids, therefore, has an indirect effect on the activity of monocytes and neutrophils (Calder, 2006). Further, ALA has a protective function, preventing considerable intensification of inflammatory conditions by lowering the expression of pro-inflammatory genes (Schmitz and Ecker, 2008).

The method of fat supplementation and assimilation of PUFA is a potential problem in feeding adult cattle because of biohydrogenation of fat taking place in the rumen. The supplementation of fat additives to MR might contribute to higher PUFA bioavailability to calves (Garcia et al., 2014b), as most of the fluids 
calves are fed bypass their rumen via the esophageal groove and are not exposed to microflora in the rumen.

Many studies have found that the addition of PUFArich fat in MR results in better production parameters of calves (Quigley et al., 2006; Daniels et al., 2008). Garcia et al. (2014b) found higher gains in the BW of calves after higher intakes of LA in MR. Watkins et al. (2001) reported increased synthesis of osseous tissue in consequence of a higher supply of ALA. Hill et al. (2011) described improved gains in BW in calves fed a mix of butyrate, coconut oil, and flax oil. The same authors reported higher daily gains in calves fed a mix of butyrate, coconut oil, and rapeseed oil (Hill et al., 2007b). Additionally, the use of flax oil alone resulted in improved BW gains in calves (Hill et al., 2009). Further, Ballou and De Peters (2008) demonstrated a slight effect of fish oil on BW gains in Jersey calves.

Currently, no detailed dietary requirements exist for particular PUFA, especially essential FA, in the feeding of ruminants (Palmquist, 2010). Assessment of the deficiency and requirements for FA should be based on analysis of health parameters (Cunnane and Guesnet, 2011), metabolic profile, and immune function (Garcia et al., 2015). The feeding of certain PUFA in MR seems appropriate, as a requirement for the FA appears to exist (Hill et al., 2007a,b; Guilloteau et al., 2009a,b; Górka et al., 2011a,b; Hill et al., 2011). Previous studies showed that apple pomace contains phenolic compounds that enhance the stability of fish and flax oils (Śpitalniak-Bajerska et al., 2018). Moreover, pomace is a good carrier for oils. The available literature lacks information on the use of flax oil esters in calf feeding; therefore, we find grounds for comparison between the natural product (flax oil) and one obtained through chemical synthesis. We hypothesized that supplementation of MR with flax oil or ethyl esters of flax oil, with lyophilized apples as a carrier, would improve calf growth and selected indices of metabolic and oxidative functions.

\section{MATERIALS AND METHODS}

\section{Animals and Treatments}

The animal study protocol was approved by the Local Ethics Committee (decision No. 63/2013, Wrocław, Poland) before the onset of the trial. The study was carried out at a commercial dairy farm in western Poland. Twenty-seven clinically healthy calves (Polish Holstein-Friesian calves) at $14 \mathrm{~d}$ of age were randomly allocated to 3 groups $(\mathrm{n}=9$ each): the control $(\mathbf{C O N})$, fed MR without added fat supplement; experimental group MRE, fed with MR supplemented with a blend ethyl esters of flax oil $(10 \mathrm{~g} / \mathrm{d})$ with lyophilized apples (25 g/d); or experimental group MRL, receiving MR with a blend flax oil $(10 \mathrm{~g} / \mathrm{d})$ with lyophilized apples $(25 \mathrm{~g} / \mathrm{d})$. Animals were divided into groups based on their age $(14 \mathrm{~d})$, BW $(40 \pm 1.65 \mathrm{~kg})$, and sex (5 females and 4 males in each group). The study lasted from d 14 to 42 of the calves' lives and was conducted in May and June. Calves were fed colostrum (10\% of birth weight) for $3 \mathrm{~d}$ and then whole milk. The MR (Polmass SA, Bydgoszcz, Poland) was mixed 1:8 with warm water (about $41^{\circ} \mathrm{C}$ ) and fed from a bucket with a teat. The MR was fed twice a day at 0700 and $1500 \mathrm{~h}$, at a constant amount of $720 \mathrm{~g}$ per day with a volume of $3 \mathrm{~L}$ each time. The fat additives were added each time before preparing the MR and mixed thoroughly. The flax seed oil and ethyl esters of flax oil with lyophilized apples were tested in laboratory conditions for stability of the FA (Śpitalniak-Bajerska et al., 2019). Calves had ad libitum access to clean, fresh water and starter (Cargill, Warsaw, Poland) at all times. The pelleted starter feed was composed of corn, wheat bran, toasted soybean meal, molassed sugar beet pulp, distillers solubles (corn-based), malt sprouts, sugar beet molasses, rapeseed meal, calcium carbonate, vegetable fats and oils (soy), and sodium chloride. The calves were housed in a ventilated barn in individual pens $(2.4 \times 1.2 \mathrm{~m})$ bedded with long wheat straw.

\section{Sampling and Measurements}

Chemical analyses were carried out on samples of the MR, pelleted forage starter for calves, hay, and lyophilized apples. Samples of MR and the starter were collected weekly and pooled. Dietary samples were analyzed for DM (method 934.01), crude fat (920.39), CP (988.05), and crude fiber (978.10; Fibertec 1020 M6 apparatus, Foss Analytics, Hillerød, Denmark), according to AOAC International (2005) procedures. The methods of Van Soest et al. (1991) were used to measure NDF and ADF. The compositions of FA in all the feeds samples and in the fat and apple additives were determined via GC-MS (Saturn Ion Trap 2000 GC/MS/MS System with CP-3800 GC, Varian Inc., Palo Alto, CA). The chemical compositions of the forage samples are shown in Table 1.

\section{Feed Intake and Body Measurements}

The starter and hay were offered daily at $0800 \mathrm{~h}$, and refusals were weighed daily throughout the experimental period (d 14 to 42 ) before preparation of solid feed, to calculate feed intake. The investigated production parameters included feed intake, ADG, and growth rate 
Table 1. Nutrient concentrations (DM basis) and fatty acid profiles of the feeds: milk replacer (MR), MR with supplement of lyophilized apples and ethyl esters extracted from flax oil (MRE), MR with supplement of lyophilized apples and flax oil (MRL), pelleted calf forage starter, and hay

\begin{tabular}{|c|c|c|c|c|c|}
\hline Item & MR & MRE & MRL & Starter & Hay \\
\hline DM $(\%)$ & 96.85 & 95.76 & 94.99 & 87.56 & 91.91 \\
\hline \multicolumn{6}{|l|}{ DM basis (\%) } \\
\hline $\mathrm{CP}$ & 23.71 & 23.45 & 23.45 & 21.14 & 12.42 \\
\hline Crude fat & 17.09 & 18.39 & 18.38 & 3.93 & 1.94 \\
\hline Crude fiber & 0.81 & 0.95 & 0.95 & 6.05 & 26.15 \\
\hline Ash & 8.18 & 8.14 & 8.15 & 5.31 & 8.86 \\
\hline $\mathrm{ADF}$ & - & - & - & 10.42 & 41.51 \\
\hline NDF & 0.53 & 0.63 & 0.62 & 27.8 & 77.42 \\
\hline \multicolumn{6}{|l|}{ Fatty acid (\%) } \\
\hline C12:0 & 1.14 & 1.04 & 1.04 & 0.02 & 0.08 \\
\hline C14:0 & 2.60 & 2.38 & 2.38 & 0.01 & 0.07 \\
\hline C16:0 & 23.1 & 21.45 & 21.57 & 0.57 & 2.79 \\
\hline C16:1 & 2.09 & 1.92 & 1.91 & 0.01 & 0.04 \\
\hline C18:0 & 14.13 & 13.44 & 13.28 & 0.09 & 0.21 \\
\hline $\mathrm{C} 18: 1$ cis and trans & 44.56 & 41.18 & 42.55 & 1.15 & 0.43 \\
\hline $\mathrm{C} 18: 2 \mathrm{n}-6$ & 8.06 & 9.06 & 8.69 & 2.35 & 1.10 \\
\hline C18:3n-3 & 1.44 & 5.60 & 5.72 & 0.18 & 2.28 \\
\hline
\end{tabular}

(Hill et al., 2011; Szymańska-Czerwińska and Bednarek, 2011).

Calves were weighed every $7 \mathrm{~d}$ until the end of the trial (platform scales WPT/4 150 C6, Radwag, Radom, Poland). Fecal score (absent to severe diarrhea) were assessed on d 14, 21, 28, 35, and 42, according to the modified methodology proposed by Sunderland et al. (2003). Fecal scores were evaluated daily based on a 0 to 3 score $(0=$ normal, $1=$ loose or sloppy feces with retained form, $2=$ loose to watery unformed feces, $3=$ profuse, watery feces). General appearance score was described as $0=$ bright, alert, responsive, normal appetite; 1 = reduced responsiveness, decreased appetite; 2 $=$ unstable standing position, depressed; $3=$ unable to stand without assistance, critical. Rectal temperature was measured weekly before morning feeding.

\section{Blood Collection and Analysis}

Laboratory blood tests were conducted on d 14, 21, 28, 35, and 42. Blood samples were taken from the external jugular vein at the beginning of the trial and then weekly, $4 \mathrm{~h}$ after liquid feeding. Blood was collected into sterile test tubes for serum (Sarsted, Nümbrecht, Germany) into tubes with anticoagulant (EDTA-K3; Sarsted), tubes containing EDTA (Labelians, Nemours, France), and tubes filled with heparin sodium salt (Sarsted). The blood samples for serum or plasma were centrifuged at $3,000 \times g$ for $10 \mathrm{~min}$ at room temperature $2 \mathrm{~h}$ from collection, and the samples were frozen $\left(-20^{\circ} \mathrm{C}\right)$ until analysis. Laboratory analyses of blood serum were performed using an ABX Pentra 400 biochemical analyzer (Horiba, Montpellier, France) and reagents from Horiba and Randox (Crumlin, UK).
The following parameters were estimated: glucose by oxidase method (Horiba reagent \#A11A01668); nonesterified fatty acids (NEFA) via enzymatic method (Randox reagent \#FA115); triglycerides (TG; Randox reagent \#A11A01640) and total cholesterol by enzymatic methods (Horiba reagent \#A11A01634); high-density lipoprotein (HDL; Horiba reagent \#A11A01636) and low-density lipoprotein (LDL; Horiba reagent \#A11A01638) cholesterols by colorimetric assay (Horiba reagent \#A11A01634). The following parameters of antioxidant status were also determined: total antioxidant capacity (TAS; Randox reagent \#NX2332) in serum by the colorimetric method based on ABTS [2,2'-azino-bis(3-ethylbenzo-thiazoline6 -sulfonic acid)] with peroxidase; glutathione peroxidase (GPx; Randox reagent Ransel \#RS504) in whole blood by enzymatic method; and superoxide dismutase (SOD; Randox reagent Ransod \#SD125) in erythrocytes by the spectrophotometric method based on a reaction with INT [2-(4-iodophenyl)-3-(4-nitrophenol)5 -phenyltetrazolium chloride].

The concentration of malondialdehyde (MDA) in blood serum was found using the bovine MDA ELISA kit from MyBioSource (San Diego, CA; assay kit \#MBS2609485). Immunological parameters were determined in serum. Serum IgG and IgM were assayed using ELISA kits from Bethyl Laboratories (Montgomery, AL; assay kits \#E10-118 and \#E10-101, respectively). Tumor necrosis factor (TNF- $\alpha$ ) was assayed in serum with the Bovine Tumor Necrosis Factor ELISA Kit from MyBioSource (assay kit \#MBS2611057). Serum IL-6 was assayed using the Bovine Interleukin-6 ELISA Kit immunoassay from MyBioSource (assay kit \#MBS038658). These measurements were conducted 
using a Synergy fluorescence, luminescence, and absorbance reader from BioTek Instruments (Winooski, VT).

\section{Blood Serum Fatty Acid Profile}

The method described by Folch et al. (1957) was used for lipid extraction from blood serum. The blood serum $(1 \mathrm{~mL})$ was added to $0.5 \mathrm{~mL}$ of a chloroform-methanol mixture $(2: 1, \mathrm{vol} / \mathrm{vol})$ and $160 \mu \mathrm{L}$ of an internal standard (17:0). The resulting material was centrifuged, and the bottom phase was collected into a heart-shaped flask. The procedure was carried out in quadruplicate. Fatty acid methyl esters were obtained by collecting the bottom phase (containing the FA fraction) of approximately $1.5 \mathrm{~mL}$, followed by evaporation. The dry residue was combined with $2 \mathrm{~mL}$ of $7 \%$ methanolic solution of potassium hydroxide and hydrolyzed in a heart-shaped glass flask at the solvent boiling temperature for $5 \mathrm{~min}$. The resulting salts of $\mathrm{FA}$ were esterified by adding $3 \mathrm{~mL}$ of $14 \%$ methanolic solution of boron trifluoride and maintaining the mix at the boiling temperature for $5 \mathrm{~min}$. After completing the reaction, 15 $\mathrm{mL}$ of cyclohexane was added, and the organic fraction was washed with sodium hydroxide $(2 \times 10 \mathrm{~mL})$ and brine to obtain a neutral $\mathrm{pH}$. The organic solution was dried over anhydrous sodium sulfate. After the solvent was concentrated, the resulting esters were kept at $-20^{\circ} \mathrm{C}$ until GC analysis. The procedure was carried out according to the method developed by Maślak et al. (2015), taking into account the guidelines described in PN-EN ISO 12966-1:2015-01 (Polish Committee for Standardization, 2015).

The FA profiles of the obtained samples were analyzed using a GC apparatus coupled with an MS (Saturn Ion Trap 2000 GC/MS/MS System with CP-3800 GC, Varian Inc.). The separation was effected using a nonpolar column ZB WAX MS (Zebron, $30 \mathrm{~m} \times 0.25 \mathrm{~mm} \times 0.25$ $\mu \mathrm{m}$ film; Phenomenex Torrance, CA). The measurements were carried out via electron impact ionization under the following conditions: ionization $70 \mathrm{eV}$, rate 1 scan per second, split ratio 1:40. The temperature program was as follows: heating rate $5^{\circ} \mathrm{C} / \mathrm{min}$ from $80^{\circ} \mathrm{C}$ to $200^{\circ} \mathrm{C}$, then $25^{\circ} \mathrm{C} / \mathrm{min}$ to $260^{\circ} \mathrm{C}$, injector temperature $220^{\circ} \mathrm{C}$, helium gas carrier $1 \mathrm{~mL}$ per minute. Analyses were carried out with ion collection in the range $(\mathrm{m} / \mathrm{z})$ from 39 to 300, with electron impact ionization of 70 $\mathrm{eV}, 1$ scan per second.

Identification of blood serum FA was carried out using 3 different analytical methods: (1) comparison of the mass spectrum of an unknown compound with the mass spectrum in NIST14; (2) comparison of retention times and mass spectra with chromatographic standards (Mix-37, Sigma-Aldrich, St. Louis, MO); and
(3) comparison of Kovacs retention indices, as found logarithmically with respect to linear n-alkanes, with reference values read out in NIST14 and NIST databases (https://webbook.nist.gov/).

\section{Statistical Analysis}

Data were analyzed using a general linear model for repeated measures based on the MIXED procedure of SAS (version 9.2; SAS Institute Inc., Cary, NC). For repeated measures, the model included the effect of dietary treatments (D) and sampling time (T) as fixed effects and their interactions $(\mathrm{D} \times \mathrm{T})$, according to the following model:

$$
\mathrm{Y}_{\mathrm{ijk}}=\mu+\alpha_{\mathrm{i}}+\beta_{\mathrm{j}}+\alpha \beta_{\mathrm{ij}}+\varepsilon_{\mathrm{ijk}}
$$

where $Y_{\mathrm{ijk}}$ is the dependent variable; $\mu$ is an overall mean; $\alpha_{\mathrm{i}}$ is the dietary treatment effect ( 3 groups); $\beta_{\mathrm{j}}$ is a series of blood tests $(1,2,3,4,5) ; \alpha \beta_{\mathrm{ij}}$ is the treatment effect $\times$ series of tests; and $\varepsilon_{\mathrm{ijk}}$ is the random residual error.

The same statistical model was applied for ADG, $\mathrm{ME}$, growth rate, MR intake, starter intake, feed efficiency, FA intake, and parameters of health status. These data were analyzed as repeated measures using the MIXED procedure of SAS with measurement day as the repeated variable used for estimated time effect $\beta \mathrm{j}$ factor $(1,2,3, \ldots, \mathrm{n})$. Before analyses, all data were screened for normality using the UNIVARIATE procedure of SAS. Means were compared with Duncan's test. The data are presented as average values and standard error of the mean. Significant differences were declared at $P<0.05$ and tendencies at $P<0.10$.

\section{RESULTS}

\section{Growth, Intake, and Overall Health}

Performance information is included in Table 2. The amount of MR given to calves was constant throughout the experiment. During the research period, we observed differences in starter intake over time $(P<0.01)$ and between treatments $(P<0.04)$. Some differences $(P<0.01)$ were observed in feed efficiency between the treatment groups. Supplementation had no significant effect on higher BW gains in the MRE and MRL groups compared with CON; however, the highest BW was assessed in the MRE group. For CON, the average value of feed efficiency was the lowest, and ADG gains were also the lowest. Intake of $\mathrm{C} 18: 1 \mathrm{n}-9, \mathrm{C} 18: 3 \mathrm{n}-3$, and C18:2n-6 acids were higher in calves fed the treatments than in CON. 
Some health parameters, such as rectal temperature, fecal score, and days with diarrhea, are shown in Table 2. Higher rectal temperatures were observed in MRE and MRL calves compared with the control group $(P<$ $0.01)$. On the other hand, the fecal score was statistically decreased for the MRE and MRL groups. Most importantly, we did not observe any clinical symptoms of diarrhea during the experimental period.

\section{Blood Parameters}

The biochemical parameters of blood varied irregularly during the experiment (Figure 1). Means of NEFA concentration did not differ between the groups. On d 42 of life, NEFA levels were highest in the MRE group $(P<0.01)$. The MRL group calves had a significantly lower $(P<0.01)$ level of glucose before d 28 of life, followed by an increase continuing until $d 42$. Changes in the MRE group consisted of a continual drop in glucose levels during the experiment. The highest average HDL was in the in the MRL group, as were total cholesterol values.

Blood serum TAS values increased with calf age. The lowest average value of TAS was detected in the MRE group and the highest in the MRL group $(P<$ 0.01). On d 42 of life, TAS was $1.90 \mathrm{mmol} / \mathrm{L}$ and 1.28 $\mathrm{mmol} / \mathrm{L}$ for MRL and CON, respectively (Figure 2). The MRE group showed significantly lower $(P<0.01)$ GPx activity compared with the other groups. The highest average GPx activity was observed in the MRL group (especially from d 28 to 42 of life). During the experiment, the control group showed decreasing GPx activities. The highest average SOD activity $(P<0.01)$ occurred in the MRL group (Figure 2).

We found statistical differences $(P<0.01)$ in average MDA concentrations between the groups. On d 21 of life, MDA increased observably $(P<0.01)$ in the MRE group, to a much higher value than in the other groups. Such differences were also seen on d 28 of life. The level of MDA tended to decrease with calves' age, in comparison with that for d 21 of life.

The additives were not found to have a significant effect on the concentration of IL-6, which was observed to slightly increase on d 42 of life (MRE and MRL). Supplementation and age had considerable effects on the level of TNF- $\alpha(P<0.01)$. In the experimental groups, the values of TNF- $\alpha$ on d 14, 21, and 35 of life were significantly lower $(P<0.01)$ compared with $\mathrm{CON}$ (Figure 3). Variations in blood serum concentrations of IgG were age-related $(P<0.01)$. Supplementation was not found to have a significant effect on $\mathrm{IgG}$ concentration between the groups. Levels of IgG increased after d 21 of life in the MRL group and after d 28 of life in MRE. Moreover, calf age was found to have a significant $(P<0.01)$ effect on variations in IgM levels. Higher concentrations of $\mathrm{IgM}$ were recorded on d 28 of life in the MRE group compared with the CON group.

\section{Fatty Acid in Blood}

The fat additives had a significant effect on variations in the levels of most of the FA determined in calves' blood serum in this experiment (Table 3). Significant relationships $(P<0.01)$ were observed between

Table 2. Performance of calves fed fat-apple supplement (with ethyl ester of flax oil or flax oil) and fatty acid intake

\begin{tabular}{|c|c|c|c|c|c|c|c|}
\hline Item & \multicolumn{3}{|c|}{$\operatorname{Diet}^{1}$} & SEM & \multicolumn{3}{|c|}{$P$-value } \\
\hline $\begin{array}{l}\text { Maximum MR intake }{ }^{2}(\mathrm{~kg} \text { of DM/d) } \\
\text { Fatty acid intake }(\mathrm{g} / \mathrm{d})\end{array}$ & 0.72 & 0.72 & 0.72 & - & - & - & - \\
\hline C12:0 & 8.71 & 8.71 & 8.65 & 0.01 & - & - & - \\
\hline C14:0 & 19.58 & 19.59 & 19.58 & $<0.001$ & - & - & - \\
\hline C16:0 & 177.72 & 179.36 & 179.22 & 0.01 & 0.11 & 0.09 & 0.25 \\
\hline C18:1n-9 & 343.22 & 345.61 & 349.94 & 0.01 & 0.01 & $<0.01$ & 0.18 \\
\hline C18:2n-6 & 78.87 & 87.13 & 82.99 & 0.08 & 0.02 & 0.012 & 0.18 \\
\hline $\mathrm{C} 18: 3 \mathrm{n}-3$ & 12.21 & 29.87 & 30.16 & 0.01 & 0.01 & $<0.01$ & 0.87 \\
\hline Starter intake $(\mathrm{kg}$ of $\mathrm{DM} / \mathrm{d})$ & 0.28 & 0.29 & 0.27 & 0.01 & 0.04 & $<0.01$ & 0.06 \\
\hline $\mathrm{ME}^{3}(\mathrm{Mcal} / \mathrm{kg}$ of $\mathrm{DM})$ & 3.26 & 3.57 & 3.71 & 0.12 & 0.38 & 0.01 & 0.02 \\
\hline $\operatorname{ADG}(\mathrm{g} / \mathrm{d})$ & 566.99 & 593.17 & 588.27 & 22.43 & 0.90 & 0.01 & 0.64 \\
\hline Feed efficiency & 0.50 & 0.59 & 0.58 & 0.06 & 0.01 & 0.14 & 0.01 \\
\hline
\end{tabular}

${ }^{1} \mathrm{CON}=$ control group; $\mathrm{MRE}=$ experimental group supplemented with milk replacer with flax oil of ethyl esters and lyophilized apples; MRL $=$ experimental group supplemented with milk replacer with flax oil and lyophilized apples.

${ }^{2} \mathrm{MR}=$ milk replacer.

${ }^{3}$ Calculated from NRC (2001). 

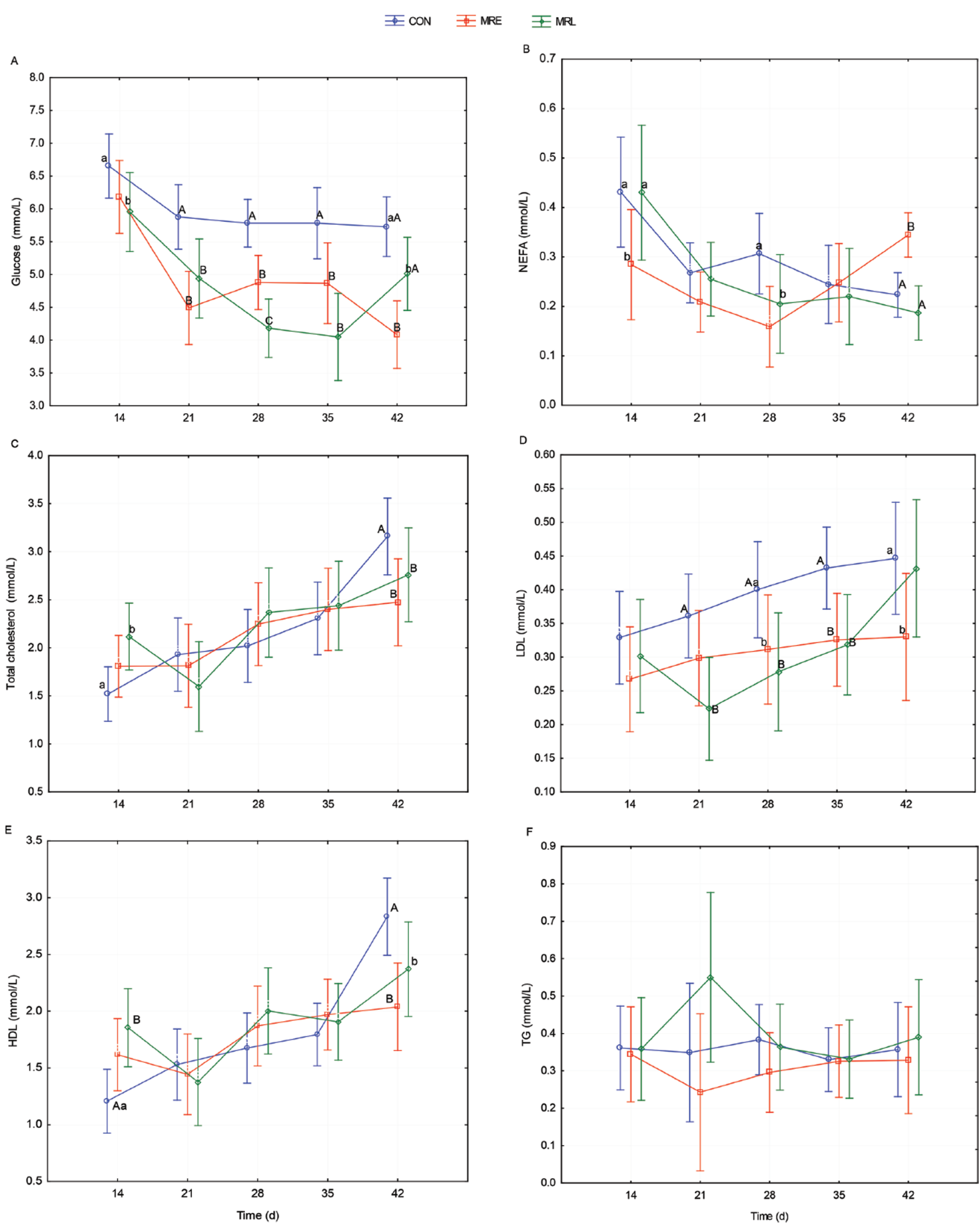

Figure 1. Average values of carbohydrate-lipid metabolism parameters in calf serum. (A) Glucose; (B) nonesterified fatty acids (NEFA); (C) total cholesterol; (D) low-density lipoprotein (LDL); (E) high-density lipoprotein (HDL); (F) triglycerides (TG). CON = control group; MRE = group receiving ethyl esters with lyophilized apples; MRL = group receiving flax oil with lyophilized apples. Values with different lowercase letters differ between treatments within a sampling time $(P<0.05)$; values with different uppercase letters differ between treatments within a sampling time $(P<0.01)$. Error bars represent SEM (9 calves per group). 
the groups in relation to the level of palmitic (C16:0), palmitooleic (C16:1), stearic (C18:0), linoleic (C18:2n -6), $\alpha$-linolenic (C18:3n-3) and oleic (C18:1) acids. Only differences in the blood serum levels of palmitic (C16:0) and linoleic (C18:2n-6) acids were age-related. Among the saturated acids, the highest average concentrations were detected for $\mathrm{C} 16: 0$ and $\mathrm{C} 18: 0$ in the $\mathrm{CON}$ group $(P<0.01)$. It was noted that, with calf age in the MRE and MRL groups, the levels of the SFA C16:0 and C18:0 tended to decrease gradually, whereas the levels of the unsaturated acids C18:2n-6 and C18:3n-3 tended to increase $(P<0.01)$. The average concentration of C18:3n-3 for the duration of the experiment was highest in the MRE group $(P<0.01)$. Additionally, average levels of the palmitic acid C16:0 were lower $(P<0.01)$ in the experimental groups than in the control group.

\section{DISCUSSION}

Several studies have demonstrated that the use of various fats in MR or starter as feed for preweaned calves might promote the development of immune
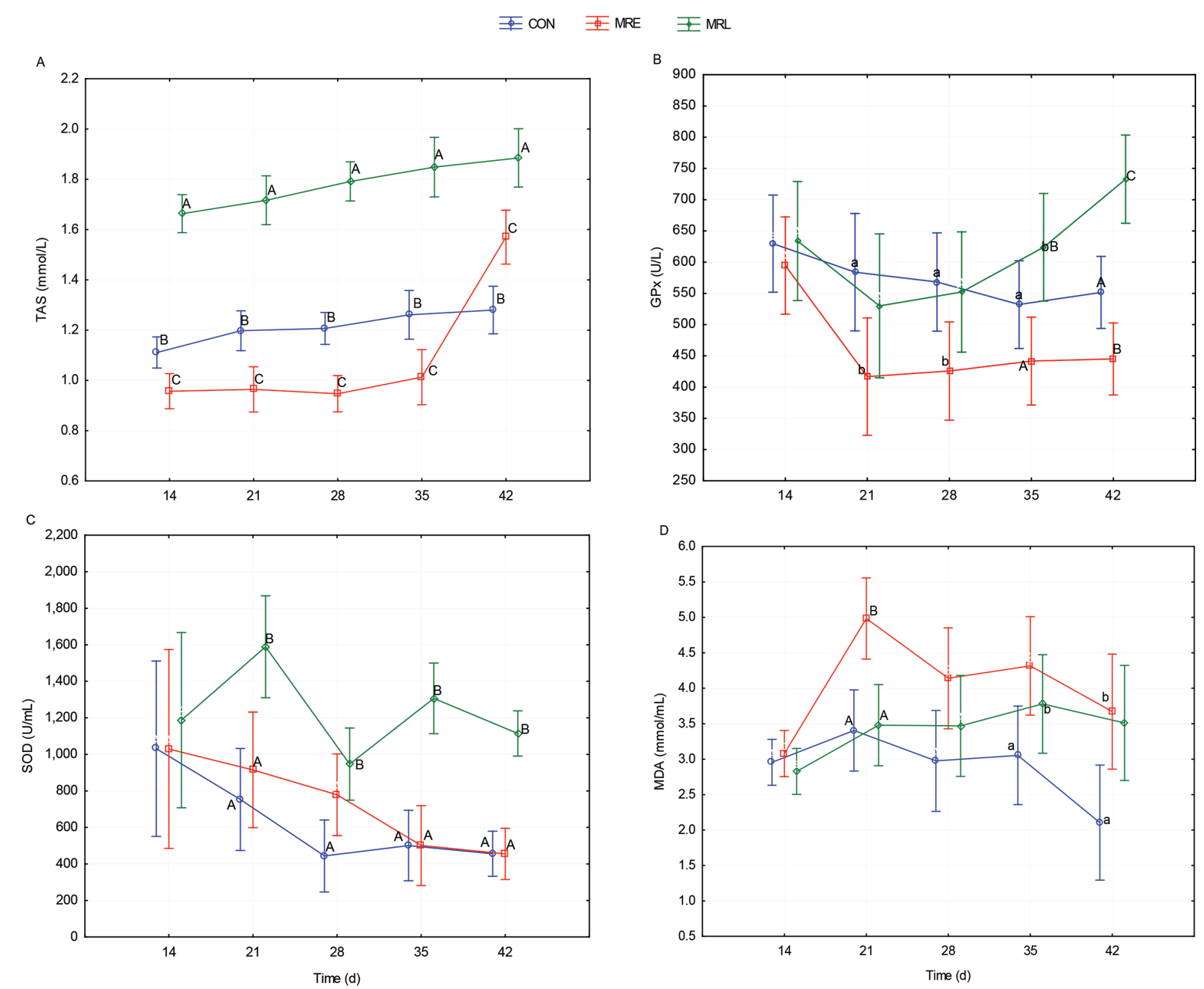

Figure 2. Indicators of antioxidant status in the blood of calves. (A) Total antioxidant capacity (TAS); (B) glutathione peroxidase (GPx); (C) superoxide dismutase (SOD); (D) malondialdehyde (MDA). CON = control group; MRE = group receiving ethyl esters with lyophilized apples; MRL = group receiving flax oil with lyophilized apples. Values with different lowercase letters differ between treatments within a sampling time $(P<0.05)$; values with different uppercase letters differ between treatments within a sampling time $(P<0.01)$. Error bars represent SEM (9 calves per group). 
responses and health (Hill et al., 2011; Garcia et al., 2015; Garcia et al., 2016; Kadkhoday et al., 2017).

Body weight gains recorded for calves in our studies were within the range of values recorded in other studies on preweaned calves (Hill et al., 2007a, b; Bateman et al., 2012). Results of the effects of various fat additives used for calves are disparate. The highest ADG $(593.17 \mathrm{~g} / \mathrm{d})$ were recorded after using ethyl esters of flax oil (MRE group). Increased BW gains were also seen in the calves fed flax oil (MRL), compared with the control group. A beneficial effect of forage types with flax oil in various forms for BW gains has been described by other authors (Hill et al., 2009; Hill et al., 2011; Karcher et al., 2014). According to Garcia et al. (2014b), the effect of increasing BW gains through supplementation with PUFA (including LA) is believed to result from the function of LA in cell membranes and in myoblast synthesis. A lack of effect of additives rich in $\mathrm{n}-3$ acids on improvement in BW gains might result from physiological functions and increased demand on ALA, eicosapentaenoic acid (EPA), and docosahexaenoic acid (DHA) in nervous tissue development early in a calf's life (Karcher et al., 2014).

In the present studies, calves in the control group consumed a lower average amount of starter and had lower ADG compared with the MRL group. The use
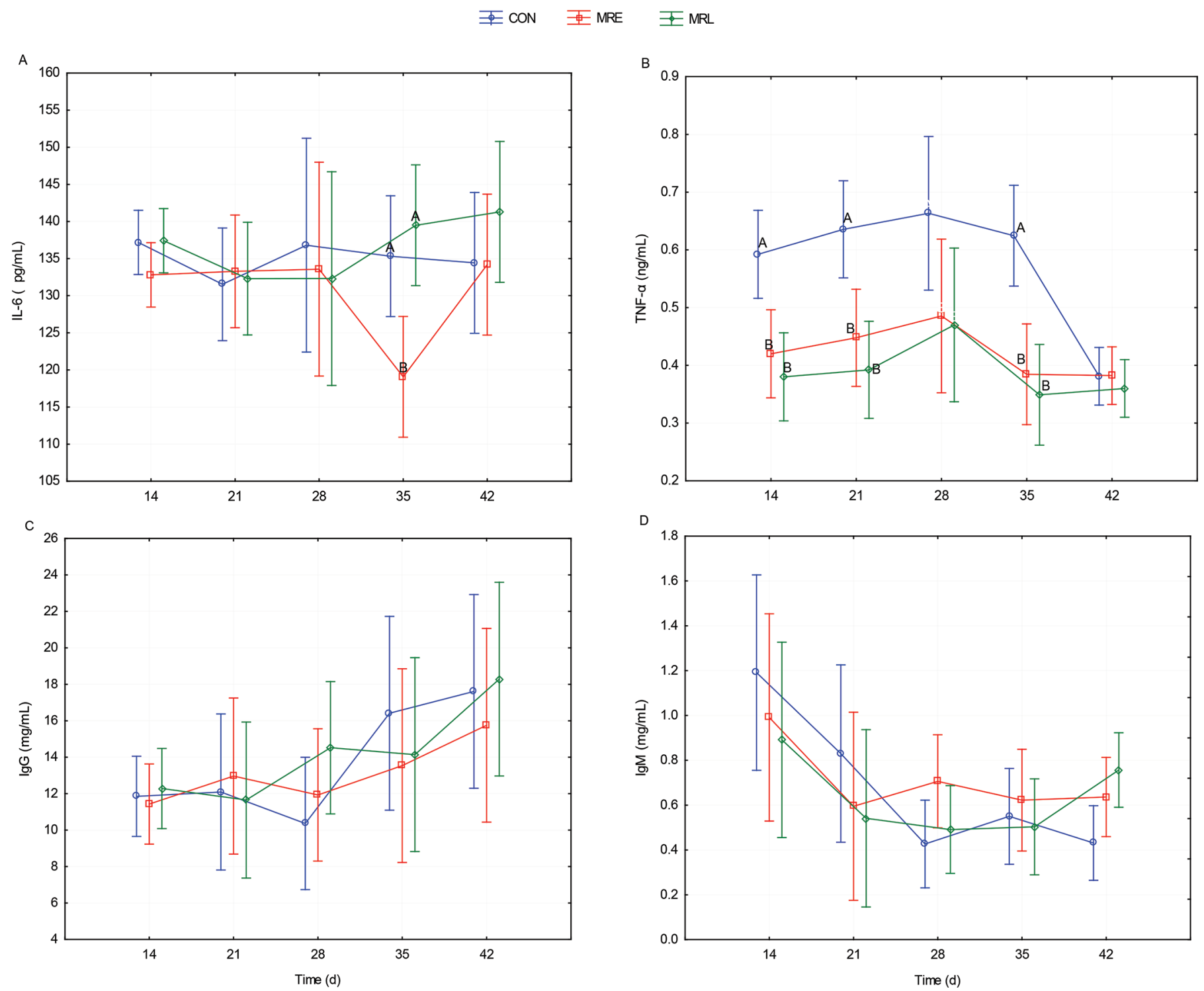

Figure 3. Average values of immunological parameters. (A) IL-6; (B) tumor necrosis factor- $\alpha$ (TNF- $\alpha$ ); (C) IgG; (D) IgM. CON = control group; $\mathrm{MRE}=$ group receiving ethyl esters with lyophilized apples; MRL = group receiving flax oil with lyophilized apples. Values with different uppercase letters differ between treatments within a sampling time $(P<0.01)$. Error bars represent SEM (9 calves per group). 
of vegetable fats adversely affected the intake of the starter feed, as in other studies (Hill et al., 2007a, b). Perhaps adding fats to MR might cause a substitution effect, resulting in lower intake of the starter feed. In the MRE group, intake of starter feed was the highest. This might be attributable to the lower caloric value of the esters $(10 \mathrm{~g}=116.4 \mathrm{kcal})$ compared with flax oil (10 $\mathrm{g}=135 \mathrm{kcal}$ ), in which FA are present as triglycerides. In a study of calves fed linseed or fish oil, Karcher et al. (2014) observed higher intakes of solid feed compared with the control group. In the same studies, the highest values of feed efficiency and the highest average daily BW gains were recorded for the calves fed linseed oil (Karcher et al., 2014). In the present studies, the value of feed efficiency was significantly higher $(P<0.01)$ for the experimental groups compared with the control group. No calves were sick during the experiment. The average fecal score tended to be lower for calves fed treatments compared with the control.

Total cholesterol, TG, and glucose are significant indicators of the body's energy profile. In this study, an increased supply of PUFA increased $(P<0.01)$ blood serum levels of HDL and decreased those of LDL in the experimental groups. Specifically, higher HDL levels were observable in the MRL group, where TG content was higher as well. In other studies, the supply of n-3 FA with fish oil also resulted in higher TG levels in calves (Ballou et al., 2008). Both experimental groups had lower average levels of cholesterol. In humans, the use of ethyl esters of n-3 FA markedly improved lipid management in the body (Davidson et al., 2007; Maki et al., 2008). Bryhn et al. (2006) found a significant decrease in total cholesterol and LDL fraction in human subjects treated with n-3 FA in the form of ethyl esters. This study also demonstrated that administration of ethyl esters of flax oil did not result in higher blood serum levels of TG in calves. On the other hand, an excess of fats in animal diets might cause excessively high TG levels, frequently leading to metabolic disorders in ruminants (Khan et al., 2011). Increased insulin levels resulting from higher consumption of forage might lead to lower blood serum levels of glucose (Cabaraux et al., 2004). In both experimental groups, blood serum levels of glucose were lower than in the control group. The FA contribution is not enough to promote adequate glycemia.

When apples are used as a carrier for fat additives (Tsao et al., 2005; Śpitalniak-Bajerska et al., 2018), they are a source of antioxidants, with high levels of polyphenols. On the other hand, polyphenols have a beneficial effect on the stability of FA (ŚpitalniakBajerska et al., 2018).

Lipid peroxidation is one of the indicators of oxidative stress (Mila-Kierzenkowska et al., 2016). Increased lipid peroxidation tends to inhibit the body's antioxidant system (Noeman et al., 2011). In the present study, an extra supply of fat with the addition of lyophilized apples resulted in higher blood serum levels of MDA, indicating intensified lipid peroxidation. The highest average MDA levels occurred in the group fed MRE with lyophilized apples; this was accompanied by the lowest average values of TAS, SOD, and GPx, which are important in the deactivation of oxygen free radicals. According to Noeman et al. (2011), a high-fat diet reduced the activity of antioxidant enzymes (SOD, GPx) in rats, whereas MDA levels were higher, indicating oxidative stress. Additionally, in a study on sheep, intensified lipid peroxidation was detected perinatally as an effect of higher dietary supply of PUFA (Fassah et al., 2015).

Table 3. Mean concentrations of fatty acids in blood serum of calves $(\mathrm{mg} / \mathrm{mL})$

\begin{tabular}{|c|c|c|c|c|c|c|c|}
\hline \multirow[b]{2}{*}{ Item } & \multicolumn{3}{|c|}{$\operatorname{Diet}^{1}$} & \multirow[b]{2}{*}{ SEM } & \multicolumn{3}{|c|}{$P$-value } \\
\hline & $\mathrm{CON}$ & MRE & MRL & & Diet (D) & Time $(\mathrm{T})$ & $\mathrm{D} \times \mathrm{T}$ \\
\hline C14:0 & 3.02 & 2.69 & 3.18 & 1.31 & 0.58 & 0.05 & 0.01 \\
\hline C16:0 & 25.88 & 20.96 & 16.74 & 1.21 & $<0.01$ & 0.01 & 0.02 \\
\hline C16:1 & 1.89 & 0.58 & 1.13 & 0.97 & 0.01 & 0.91 & 0.45 \\
\hline C18:0 & 20.33 & 19.02 & 18.91 & 0.93 & 0.01 & 0.43 & 0.35 \\
\hline C18:1 cis-9 & 21.22 & 20.45 & 20.61 & 0.93 & 0.05 & 0.75 & 0.23 \\
\hline C18:1 trans -9 & 1.28 & 0.91 & 1.59 & 1.07 & 0.04 & 0.64 & 0.06 \\
\hline C18:2n-6 & 19.98 & 24.96 & 28.78 & 1.37 & $<0.01$ & 0.01 & 0.20 \\
\hline C18:3n-6 & 0.32 & 0.87 & 0.36 & 1.42 & 0.35 & 0.11 & 0.05 \\
\hline C18:3n-3 & 0.89 & 4.33 & 3.34 & 1.08 & $<0.01$ & 0.19 & 0.72 \\
\hline Other $n-3^{2}$ & 0.47 & 0.60 & 0.53 & 0.43 & 0.66 & 0.96 & 0.04 \\
\hline Other $n-6^{3}$ & 4.15 & 4.28 & 3.95 & 0.32 & 0.93 & 0.58 & 0.32 \\
\hline
\end{tabular}

${ }^{1} \mathrm{CON}=$ control group; MRE $=$ experimental group supplemented with milk replacer with flax oil of ethyl esters and lyophilized apples; MRL = experimental group supplemented with milk replacer with flax oil and lyophilized apples.

${ }^{2}$ Total of C20:5n-3, C22:5n-3, and C22:6n-3.

${ }^{3}$ Total of C20:2n-6, C20:3n-6, and C20:4n-6. 
In the MRE group, decreasing MDA levels were observed for longer durations of the experiment, whereas the level of GPx in that group was low throughout the research period. Higher MDA levels might also be attributable to higher supplies of n-3 FA from ethyl esters of flax oil, as indicated by higher blood serum levels of ALA. The use of MRL with lyophilized apples also contributed to higher MDA levels, although the values were lower than in the MRE group. Noeman et al. (2011) demonstrated a negative correlation of MDA with GPx and SOD. Higher activity of GPx in the blood serum for the MRL group might also be indicative of the body being ready to cope with reactive oxygen species. Antioxidant enzymes are capable of responding quickly in situations when cell damage is imminent (Chaudière and Ferrari-Iliou, 1999). Higher activity of such enzymes during the experiment might also result from the body adapting itself to moderate regular oxidative stress conditions (Mila-Kierzenkowska et al., 2016). In other studies, the activity of GPx in cows was not observably affected by the use of linseed oil or linseed itself (Lima et al., 2015). Decreased activity of antioxidant enzymes and increased lipid peroxidation might also result from disorders related to environmental effects such as noise (Demirel et al., 2009). Higher activity of SOD is a first line of defense against intensified oxidative processes in the cells. According to Celi et al. (2010), lower SOD levels observed postnatally in goats were related to lower production of reactive oxygen species in the body. In the present study, supplementation in the MRL group resulted in higher levels of SOD and MDA. Higher activity of SOD in that group might be indicative of a higher degree of oxidative stress. This might also have resulted from the used amounts of our preparations. Similar relationships in cows were reported by other authors (Bernabucci et al., 2005).

Use of additives rich in polyphenols and n-3 PUFA, especially the MRL supplement, observably reduced the level of TNF- $\alpha$. In other studies, use of flax oil in calves also reduced the level of TNF- $\alpha$ (Karcher et al., 2014). Fish oil caused greater reductions in TNF- $\alpha$ levels than did flax oil (Karcher et al., 2014). Increased levels of TNF- $\alpha$ may stimulate lipolysis and lead to higher concentrations of free FA in the blood, potentially resulting in higher insulin resistance and disturbed liver function, and causing excess glucose production (Das, 2008). In the present study, the use of MRL significantly inhibited any increase in TNF- $\alpha$ levels, whereas the content of IL-6 in the blood was higher. Differences between the groups were confirmed on $\mathrm{d} 35$ of life $(P<0.01)$. According to Tanaka et al. (2014), IL-6 might have multiple functions, stimulating inflammatory conditions and inhibiting TNF- $\alpha$ production
(Tokarz-Deptuła et al., 2011). The influence of food on TNF- $\alpha$ levels is, to some extent, confirmed by other studies (Hulbert et al., 2011; Kupczyński et al., 2017).

In both experimental groups, increased levels of IL-6 were accompanied by a decrease in TNF- $\alpha$. In CON, such relationships were not detected. Similar results after using a mixture of butyrate with flax oil and coconut oil for feeding calves were obtained by Hill et al. (2011). Fish oil was also found to inhibit TNF- $\alpha$ expression in calves after an Escherichia coli lipopolysaccharide challenge (Karcher et al., 2014). Lower values of TNF- $\alpha$ compared with control groups were also found after feeding MR with iron-protein chelates added (Kupczyński et al., 2017). Other studies provide evidence of an inhibitory effect of n-3 FA on the increase in IL-6 levels triggered by chronic inflammation, which is also called low-intensity inflammatory condition, and by neoplastic growths (Devarajan and Huang, 2009). Serum IgG concentrations of dairy calves that achieved a passive transfer of immunity declined at a rate of approximately $0.7 \mathrm{mg} / \mathrm{mL}$ per day in the neonatal period (Wilm at al., 2018). We observed a similar tendency in our study, and supplementation had no significant effect on IgG levels.

When analyzing variations in PUFA levels, we detected a significant $(P<0.01)$ effect on concentrations of linoleic (LA, C18:2n-6) and $\alpha$-linolenic acids (ALA, C18:3n-3). Average LA concentration in the MRL group was $28.78 \mathrm{mg} / \mathrm{mL}$, which is much higher $(P<$ $0.01)$ than that of CON. The highest average ALA content $(4.33 \mathrm{mg} / \mathrm{mL})$ was recorded in the MRE group. Differences compared with CON $(0.89 \mathrm{mg} / \mathrm{mL})$ were confirmed $(P<0.01)$. On d 35 of life, the group fed MRE was found to have a considerably higher $(P<$ 0.01) level of C18:3n-3 compared with the calves fed MRL.

The FA profile of blood depends on the amount and quality of dietary or endogenously synthesized fat, as well as the demand on and consumption of fat burnt up in energy processes or incorporated into cell membranes or storage tissue (Visioli et al., 2006). In this study, we found that the increase in blood serum levels of LA (C18:2n-6) and ALA (C18:3n-3) with diet was significant $(P<0.01)$, and concentrations of $\mathrm{C} 18: 1$ and SFA were reduced. Most of the FA present in plasma, especially long-chain FA, are derived from food (Visioli et al., 2006). The body tends to deposit nutrients to save energy, so endogenous synthesis of FA is minimized; therefore, any processes involved in modification of the blood FA profile by dietary means should be effective (Visioli et al., 2006). Changes in the FA profile to the benefit of PUFA as a result of supplementation with soybean oil were also detected in liver triglycerides and phospholipids. Changes in FA levels in the body 
might be an effect of acid substitution (Mohrhauer and Holman, 1963; Garcia et al., 2015, 2016). Garcia et al. (2015) observed an increase in the concentrations of C18:3n-3 and C22:5n-3 after using a higher dosage of soybean oil and decreases in C20:3n-9 and C18:2n -6 . The different plasma levels of the respective FA in calves are age-related: older calves are fed more solid forage compared with younger ones; in addition, rumen microflora develops, and the processes of biohydrogenation of UFA take place (Garcia et al., 2014a). Higher blood serum levels of PUFA in the present study might be indicative of their good distribution into the tissues. The higher blood serum level of ALA in the calves fed MRE might suggest a high assimilability of FA in that form. However, in other studies, where EPA and DHA were used for ethyl esters of flax oil, their assimilability was lower than in the case of the triglyceride form, which might be indicative of the digestive potential of pancreatic lipase (Kolanowski, 2013), which has a lower ability to hydrolyze ethyl esters compared with TG (Bézard et al., 1994; Visioli et al., 2006). The rate of hydrolysis of ethyl esters of EPA and DHA might be 3 times slower than that of EPA and DHA in the TG form (Bézard et al., 1994; Visioli et al., 2006).

The results of this study showed the positive effects of dietary lipid and apple preparations on the growth and health of calves. However, the most effective method of fat supplementation (as flax oil or as ethyl esters of flax oil) was not defined adequately. We have demonstrated for the first time, to the best of our knowledge, that the method of fat supplementation with lyophilized apples might differentially affect performance and some metabolic intermediates in preweaned calves.

\section{CONCLUSIONS}

Milk replacer containing n-3 FA and lyophilized apples beneficially influenced production and physiological parameters in calves. Such functional additives to MR for young calves result in higher PUFA supplies to the organism and are a source of antioxidants. However, long-term and detailed studies are needed to estimate the influence of preparations including n-3 acids and polyphenols on metabolic transformations and development of calves, such as the development of adipose and gland tissue in heifer udders.

\section{ACKNOWLEDGMENTS}

This project was supported by Wroclaw Centre of Biotechnology (Poland), Leading National Research Centre (KNOW) for the years 2014 to 2018. The authors declare that there are no conflicts of interest regarding the publication of this paper.

\section{REFERENCES}

AOAC International. 2005. Official Methods of Analysis. 18th ed. AOAC International, Arlington, VA.

Ballou, M. A., G. D. Cruz, W. Pittroff, D. H. Keisler, and E. J. DePeters. 2008. Modifying the acute phase response of Jersey calves by supplementing milk replacer with omega-3 fatty acids from fish oil. J. Dairy Sci. 91:3478-3487. https://doi.org/10.3168/ jds.2008-1016.

Ballou, M. A., and E. J. DePeters. 2008. Supplementing milk replacer with omega-3 fatty acids from fish oil on immunocompetence and health of Jersey calves. J. Dairy Sci. 91:3488-3500. https://doi .org/10.3168/jds.2008-1017.

Bateman, H. G., II, T. M. Hill, J. M. Aldrich, R. L. Schlotterbeck, and J. L. Firkins. 2012. Meta-analysis of the effect of initial serum protein concentration and empirical prediction model for growth of neonatal Holstein calves through 8 weeks of age. J. Dairy Sci. 95:363-369. https://doi.org/10.3168/jds.2011-4594.

Bernabucci, U., B. Ronchi, N. Lacetera, and A. Nardone. 2005. Influence of body condition score on relationships between metabolic status and oxidative stress in periparturient dairy cows. J. Dairy Sci. 88:2017-2026. https://doi.org/10.3168/jds.S0022 -0302(05)72878-2.

Bézard, J., J. P. Blond, A. Bernard, and P. Clouet. 1994. The metabolism and availability of essential fatty acids in animal and human tissues. Reprod. Nutr. Dev. 34:539-568. https://doi.org/10.1051/ rnd:19940603.

Bryhn, M., H. Hansteen, T. Schanche, and S. E. Aakre. 2006. The bioavailability and pharmacodynamics of different concentrations of omega-3 acid ethyl esters. Prostaglandins Leukot. Essent. Fatty Acids 75:19-24. https://doi.org/10.1016/j.plefa.2006.04.003.

Cabaraux, J. F.. I. Dufrasne, I. Istasse, and J. L. Homick. 2004. Effects of age on plasma metabolites and hormones in finishing Belgian Blue double-muscled cull females. Anim. Sci. 78:229-235. https:// doi.org/10.1017/S1357729800054011.

Calder, P. C. 2006. Polyunsaturated fatty acids and inflammation. Prostaglandins Leukot. Essent. Fatty Acids 75:197-202. https:// doi.org/10.1016/j.plefa.2006.05.012.

Calder, P. C. 2008. The relationship between the fatty acid composition of immune cells and their function. Prostaglandins Leukot. Essent. Fatty Acids 79:101-108. https://doi.org/10.1016/j.plefa .2008.09.016.

Calder, P. C., P. Yaqoob, F. Thies, F. A. Wallace, and E. A. Miles. 2002. Fatty acids and lymphocyte functions. Br. J. Nutr. 87:31-48. https://doi.org/10.1079/BJN2001455.

Celi, P., A. D. Trana, and S. Claps. 2010. Effects of plane of nutrition on oxidative stress in goats during the peripartum period. Vet. J. 184:95-99. https://doi.org/10.1016/j.tvjl.2009.01.014.

Chaudière, J., and R. Ferrari-Iliou. 1999. Intracellular antioxidants: from chemical to biochemical mechanisms. Food Chem. Toxicol. 37:949-962. https://doi.org/10.1016/S0278-6915(99)00090-3.

Cunnane, S. C., and P. Guesnet. 2011. Linoleic acid recommendations - A house of cards. Prostaglandins Leukot. Essent. Fatty Acids 85:399-402. https://doi.org/10.1016/j.plefa.2011.09.003.

Daniels, K. M., S. R. Hill, K. F. Knowlton, R. E. James, M. L. McGilliard, and R. M. Akers. 2008. Effects of milk replacer composition on selected blood metabolites and hormones in preweaned Holstein heifers. J. Dairy Sci. 91:2628-2640. https://doi.org/10.3168/ jds.2007-0859.

Das, U. N. 2008. Essential fatty acids and their metabolites could function as endogenous HMG-CoA reductase and ACE enzyme inhibitors, anti-arrhythmic, anti-hypertensive, anti-atherosclerotic, anti-inflammantory, cytoprotective, and carioprotective molecules. Lipids Health Dis. 7:37. https://doi.org/10.1186/1476-511X-7-37.

Davidson, M. H., E. A. Stein, H. E. Bays, K. C. Maki, R. T. Doyle, R. A. Shalwitz, C. M. Ballantyne, and H. N. Ginsberg. 2007. Efficacy and tolerability of adding prescription Omega-3 fatty acids $4 \mathrm{~g} / \mathrm{d}$ to Simvastatin $40 \mathrm{mg} / \mathrm{d}$ in hypertriglyceridemic patients: An 8-week, randomized, double-blind, placebo-controlled study. Clin. Ther. 29:1354-1367. https://doi.org/10.1016/j.clinthera.2007.07 .018 . 
Demirel, R., H. Mollaoğlu, H. Yeşilyurt, K. Üçok, A. Ayçiçek, M. Akkaya, A. Genç, R. Uygur, and M. Doğan. 2009. Noise induces oxidative stress in rat. Eur. J. Gen. Med 6:20-24. https://doi.org/ $10.29333 / \mathrm{ejgm} / 82631$.

Devarajan, E., and S. Huang. 2009. STAT3 as a central regulator of tumor metastases. Curr. Mol. Med. 9:626-633. https://doi.org/10 $.2174 / 156652409788488720$.

Fassah, D. M., L. Khotijah, A. Atabany, R. R. Mahyardiani, R. Puspadini, and A. Y. Putra. 2015. Blood malondialdehyde, reproductive, and lactation performances of ewes fed high PUFA rations supplemented with different antioxidant sources. Media Peternakan 38:48-56. https://doi.org/10.5398/medpet.2015.38.1.48.

Fokkink, W. B., T. M. Hill, H. G. Bateman II, J. M. Aldrich, and R. L. Schlotterbeck. 2009. Selenium yeast for dairy calf feeds. Anim. Feed Sci. Technol. 153:228-235. https://doi.org/10.1016/j .anifeedsci.2009.06.015.

Folch, J., M. Lees, and G. H. Sloane Stanley. 1957. A simple method for the isolation and purification of total lipides from animal tissues. J. Biol. Chem. 226:497-509.

Garcia, M., L. F. Greco, M. G. Favoreto, R. S. Marsola, L. T. Martins, R. S. Bisinotto, J. H. Shin, A. L. Lock, E. Block, W. W. Thatcher, J. E. P. Santos, and C. R. Staples. 2014b. Effect of supplementing fat to pregnant nonlactating cows on colostral fatty acid profile and passive immunity of the newborn calf. J. Dairy Sci. 97:392405. https://doi.org/10.3168/jds.2013-7086.

Garcia, M., L. F. Greco, M. G. Favoreto, R. S. Marsola, D. Wang, J. H. Shin, E. Block, W. W. Thatcher, J. E. P. Santos, and C. R. Staples. 2014a. Effect of supplementing essential fatty acids to pregnant nonlactating Holstein cows and their preweaned calves on calf performance, immune response, and health. J. Dairy Sci. 97:5045-5064. https://doi.org/10.3168/jds.2013-7473.

Garcia, M., L. F. Greco, A. L. Lock, E. Block, J. E. P. Santos, W. W. Thatcher, and C. R. Staples. 2016. Supplementation of essential fatty acids to Holstein calves during late uterine life and first month of life alters hepatic fatty acid profile and gene expression. J. Dairy Sci. 99:7085-7101. https://doi.org/10.3168/jds.2015 -10472 .

Garcia, M., J. H. Shin, A. Schlaefli, L. F. Greco, F. P. Maunsell, J. E. P. Santos, C. R. Staples, and W. W. Thatcher. 2015. Increasing intake of essential fatty acids from milk replacer benefits performance, immune responses, and health of preweaned Holstein calves. J. Dairy Sci. 98:458-477. https://doi.org/10.3168/jds.2014 -8384 .

Górka, P., Z. M. Kowalski, P. Pietrzak, A. Kotunia, W. Jagusiak, J. J. Holst, P. Guilloteau, and R. Zabielski. 2011a. Effect of method of delivery of sodium butyrate on rumen development in newborn calves. J. Dairy Sci. 94:5578-5588. https://doi.org/10.3168/jds .2011-4166.

Górka, P., Z. M. Kowalski, P. Pietrzak, A. Kotunia, W. Jagusiak, and R. Zabielski. 2011b. Is rumen development in newborn calves affected by different liquid feeds and small intestine development? J. Dairy Sci. 94:3002-3013. https://doi.org/10.3168/jds.2010-3499.

Guilloteau, P., R. Zabielski, and J. W. Blum. 2009b. Gastrointestinal tract and digestion in the young ruminant: Ontogenesis, adaptations, consequences and manipulations. J. Physiol. Pharmacol. 60:37-46.

Guilloteau, P., R. Zabielski, J. C. David, J. W. Blum, J. A. Morisset, M. Biernat, J. Wolinski, D. Laubitz, and Y. Hamon. 2009a. Sodium butyrate as a growth promoter in milk replacer formula for young calves. J. Dairy Sci. 92:1038-1049. https://doi.org/10.3168/ jds.2008-1213.

Hill, T. M., J. M. Aldrich, R. L. Schlotterbeck, and H. G. Bateman II. 2007a. Effects of changing the fat and fatty acid composition of milk replacers fed to neonatal calves. Prof. Anim. Sci. 23:135-143. https://doi.org/10.15232/S1080-7446(15)30953-0.

Hill, T. M., J. M. Aldrich, R. L. Schlotterbeck, and H. G. Bateman II. 2007b. Amino acids, fatty acids, and fat sources for calf milk replacers. Prof. Anim. Sci. 23:401-408. https://doi.org/10.15232/ S1080-7446(15)30995-5.

Hill, T. M., H. G. Bateman II, J. M. Aldrich, and R. L. Schlotterbeck. 2009. Effects of changing the essential and functional fatty acid intake of dairy calves. J. Dairy Sci. 92:670-676. https://doi.org/10 .3168/jds.2008-1368.

Hill, T. M., M. J. VandeHaar, L. M. Sordillo, D. R. Catherman, H. G. Bateman II, and R. L. Schlotterbeck. 2011. Fatty acid intake alters growth and immunity in milk-fed calves. J. Dairy Sci. 94:39363948. https://doi.org/10.3168/jds.2010-3935.

Hulbert, L. E., C. J. Cobb, J. A. Carroll, and M. A. Ballou. 2011. Effects of changing milk replacer feedings from twice to once daily on Holstein calf innate immune responses before and after weaning. J. Dairy Sci. 94:2557-2565. https://doi.org/10.3168/jds.2010-3980.

Kadkhoday, A., A. Riasi, M. Alikhani, M. Dehghan-Banadaky, and R. Kowsar. 2017. Effects of fat sources and dietary $\mathrm{C}_{18: 2}$ to $\mathrm{C}_{18: 3}$ fatty acids ratio on growth performance, ruminal fermentation and some blood components of Holstein calves. Livest. Sci. 204:71-77. https: //doi.org/10.1016/j.livsci.2017.08.012.

Karcher, E. L., T. M. Hill, H. G. Bateman II, R. L. Schlotterbeck, N. Vito, L. M. Sordillo, and M. J. VandeHaar. 2014. Comparison of supplementation of n-3 fatty acids from fish and flax oil on cytokine gene expression and growth of milk-fed Holstein calves. J. Dairy Sci. 97:2329-2337. https://doi.org/10.3168/jds.2013-7160.

Khan, I. A., A. Khan, A. Hussain, A. Riaz, and A. Aziz. 2011. Hemato-biochemical alterations in cross bred cattle affected with bovine theileriosis in semi-arid zone. Pak. Vet. J. 31:137-140.

Kolanowski, W. 2013. Functions and metabolic transformations of omega-3 polyunsaturated fatty acids in human body. Bromat. Chem. Toksykol. 46.

Kupczyński, R., M. Bednarski, K. Śpitalniak, and K. Pogoda-Sewerniak. 2017. Effects of protein-iron complex concentrate supplementation on iron metabolism, oxidative and immune status in preweaning calves. Int. J. Mol. Sci. 18:E1501. https://doi.org/10 .3390/ijms18071501.

Lima, L. S., M. F. Palin, G. T. Santos, C. Benchaar, and H. V. Petit. 2015. Effects of supplementation of flax meal and flax oil on mammary gene expression and activity of antioxidant enzymes in mammary tissue, plasma and erythrocytes of dairy cows. Livest. Sci. 176:196-204. https://doi.org/10.1016/j.livsci.2015.03.015.

Maki, K. C., J. M. McKenney, M. S. Reeves, B. C. Lubin, and M. R. Dicklin. 2008. Effects of adding prescription omega-3 acid ethyl esters to simvastatin $(20 \mathrm{mg} /$ day $)$ on lipids and lipoprotein particles in men and women with mixed dyslipidemia. Am. J. Cardiol. 102:429-433. https://doi.org/10.1016/j.amjcard.2008.03.078.

Maślak, E., E. Buczek, A. Szumny, W. Szczepnski, M. Franczyk-Zarow, A. Kopec, S. Chlopicki, T. Leszczynska, and R. B. Kostogrys. 2015. Individual CLA isomers, c9t11 and t10c12, prevent excess liver glycogen storage and inhibit lipogenic genes expression induced by high-fructose diet in rats. BioMed Res. Int. 2015:535982. https://doi.org/10.1155/2015/535982.

Mila-Kierzenkowska, C., B. Augustyńska, A. Woźniak, T. Boraczyński, R. Wesołowski, P. Sutkowy, and K. Szewczyk-Golec. 2016. Effect of changes in ambient temperature on oxidative stress markers in blood of regular winter swimmers. Medycyna Ogólna i Nauki o Zdrowiu. 22:46-50.

Mohrhauer, H., and R. T. Holman. 1963. The effect of dose level of essential fatty acids upon fatty acid composition of the rat liver. J. Lipid Res. 4:151-159.

Noeman, S. A., H. E. Hamooda, and A. A. Baalash. 2011. Biochemical study of oxidative stress markers in the liver, kidney and heart of high fat diet induced obesity in rats. Diabetol. Metab. Syndr. 3:17. https://doi.org/10.1186/1758-5996-3-17.

NRC. 2001. Nutrient Requirements of Dairy Cattle. National Academy Press, Washington, DC.

Palmquist, D. L. 2010. Essential fatty acids in ruminant diets. Pages 127-141 in Proc 21st Annual Ruminant Nutrition Symposium, February 2-3, Gainesville, FL. Institute of Food and Agricultural Sciences, University of Florida, Gainesville.

Polish Committee for Standardization. 2015. PN-EN ISO 129661:2015-01, Vegetable and animal oils and fats. Gas chromatography of fatty acid methyl esters - Part 1: A guide to modern gas chromatography of fatty acid methyl esters. Polski Komitet Normalizacyjny [Polish Committee for Standardization], Warsaw, Poland. 
Quigley, J. D., T. A. Wolfe, and T. H. Elsasser. 2006. Effects of additional milk replacer feeding on calf health, growth, and selected blood metabolites in calves. J. Dairy Sci. 89:207-216. https://doi .org/10.3168/jds.S0022-0302(06)72085-9.

Schmitz, G., and J. Ecker. 2008. The opposing effects of n-3 and n-6 fatty acids. Prog. Lipid Res. 47:147-155. https://doi.org/10.1016/ j.plipres.2007.12.004.

Śpitalniak-Bajerska, K., A. Szumny, A. Z. Kucharska, and R. Kupczyński. 2018. Effect of natural antioxidants on the stability of linseed oil and fish stored under anaerobic conditions. J Chem. 2018:9375085.

Śpitalniak-Bajerska, K., R. Kupczyński, A. Szumny, A. Z. Kucharska, and A. Vogt. 2019. Lyophilized apples on flax oil and ethyl esters of flax oil-Stability and antioxidant evaluation. Open Chem. 17:831-840. https://doi.org/10.1515/chem-2019-0090.

Sunderland, S. J., P. Sarasola, T. G. Rowan, C. J. Giles, and D. G. Smith. 2003. Efficacy of danofloxacin $18 \%$ injectable solution in the treatment of Escherichia coli diarrhoea in young calves in Europe. Res. Vet. Sci. 74:171-178. https://doi.org/10.1016/S0034 $-5288(02) 00186-8$

Szymańska-Czerwińska, M., and D. Bednarek. 2011. Effect of tylosin and prebiotics on the functional state of rumen and production parameters in calves. Med. Weter. 6:412-417.

Tanaka, T., M. Narazaki, and T. Kishimoto. 2014. IL-6 in inflammation, immunity, and disease. Cold Spring Harb. Perspect. Biol. 6:a016295. https://doi.org/10.1101/cshperspect.a016295.

Tokarz-Deptuła, B., T. Miller, and W. Deptula. 2011. Cytokiny z rodziny interleukiny 1. Post. Mikrobiol. 50:217-221.
Tsao, R., R. Yang, S. Xie, E. Sockovie, and S. Khanizadeh. 2005. Which polyphenolic compounds contribute to the total antioxidant activities of apple? J. Agric. Food Chem. 53:4989-4995. https:// doi.org/10.1021/jf048289h.

Van Soest, P. J., J. B. Robertson, and B. A. Lewis. 1991. Methods for dietary fiber, neutral detergent fiber, and nonstarch polysaccharides in relation to animal nutrition. J. Dairy Sci. 74:3583-3597. https://doi.org/10.3168/jds.S0022-0302(91)78551-2.

Visioli, F., M. A. Crawford, S. Cunnane, P. Rise, and C. Galli. 2006. Lipid transport, dietary fats and endogenus lipid synthesis: hypotheses on saturation and competition processes. Nutr. Health 18:127-132. https://doi.org/10.1177/026010600601800204.

Watkins, B. A., H. E. Lippman, L. Le Bouteiller, Y. Li, and M. F. Seifert. 2001. Bioactive fatty acids: Role in bone biology and bone cell function. Prog. Lipid Res. 40:125-148. https://doi.org/10.1016/ S0163-7827(00)00016-3.

Wilm, J., J. H. Costa, H. W. Neave, D. M. Weary, and M. A. von Keyserlingk. 2018. Serum total protein and immunoglobulin G concentrations in neonatal dairy calves over the first 10 days of age. J. Dairy Sci. 101:6430-6436. https://doi.org/10.3168/jds.2017-13553.

\section{ORCIDS}

R. Kupczyński ๑ https://orcid.org/0000-0003-0796-6273 